\title{
Maximum Power Point Extraction in PV Array Under Partial Shading Conditions Using GWO-Assisted Beta Method
}

\author{
M. V. Rocha, L. P. Sampaio and S. A. O. da Silva \\ Department of Electrical Engineering \\ Federal University of Technology - UTFPR-CP, Campus of Cornélio Procópio \\ Av. Alberto Carazzai, 1640. CEP. 86.300-000 Cornélio Procópio - PR - Brazil \\ Phone number:+55(43)35204000, e-mail: maykon@alunos.utfpr.edu.br sampaio@utfpr.edu.br augus@utfpr.edu.br
}

\begin{abstract}
This paper presents a hybrid maximum power point tracking (MPPT) algorithm, which combines the grey wolf optimization (GWO) technique and Beta method for extraction of maximum power from a photovoltaic (PV) system operating under partial shading conditions. The proposed algorithm named GWO-Beta-based MPPT uses the GWO technique to achieve the global maximum power point (GMPP), while, simultaneously, the MPPT reference using Beta method is calculated according to the PV voltage and current at GMPP. After that, the MPPT algorithm is switched to operate only with the Beta method that keeps tracked on the MPP reference, guarantying the GMPP in that specific operation point. By means of computational simulation results, the performance of the proposed MPPT algorithm is evaluated taking into account the convergence speed and power oscillations to achieve the GMPP.
\end{abstract}

\section{Key words}

Grey Wolf Optimization Technique, Maximum Power Point Tracking, Beta Method, Partial Shading Conditions.

\section{Introduction}

The generation of electrical energy using photovoltaic (PV) panels presents several advantages, however, their energy conversion efficiency is still low. The efficiency record using silicon solar cells is around $25 \%$ [1], allied to fact the panels still have a high initial cost. In this way, it is mandatory to use maximum power point tracking (MPPT) techniques, in order to extract the maximum power possible from PV panels. Considering a PV panel unit, it is necessary to point out that there is only one maximum power point (MPP), which can change according to the climatic conditions, such as solar irradiation and temperature $[2,3]$.

PV arrangements present non-linear voltage versus current characteristic curves that vary according to the level of solar irradiation and temperature. Thus, the variation of the climatic conditions makes the extraction of the MPP a complex task. In order to overcome this problem, several methods employed to extract the PV array maximum power have been proposed in the literature, such as $\mathrm{P} \& \mathrm{O}$, Beta method, incremental conductance, among others [2-4].

On the other hand, when the PV array is subject to partial shading conditions, the aforementioned traditional MPPT techniques do not reach the global maximum power point (GMPP) [5, 6]. Therefore, the overall system efficiency can decrease, since a local maximum power point (LMPP) existing in the PV array PpvxVpv characteristic curve can be achieved instead the GMPP.

In order to overcome the problem of tracking the LMPP when the PV array is subjected to partial shading conditions, it has been proposed several optimization algorithms that attempt to mimic nature, such as ant colony algorithm, particle swarm algorithm, among others [6-9].

Recently, an optimization algorithm inspired in the social behavior of the grey wolves, well-known as Grey Wolf Optimization (GWO) method, has been proposed to perform the MPPT with fast convergence [9]. In [10], a combination of the GWO method with P\&O-based MPPT technique has been presented, in which the hybrid algorithm was capable to achieve the MPPT with reduced power oscillations around the MPP [10].

The main objective of this paper is the proposition of a hybrid MPPT algorithm that combines the GWO technique with the Beta method, in order to improve the convergence speed and reduce the power oscillations to achieve the GMPP. In addition, the GWO-Beta-based MPPT algorithm is compared with MPPT algorithms based on P\&O, Beta and GWO methods. The performances of the MPPT algorithms are evaluated taken into account the following cases: 1) the PV array operates at standard test condition (STC); and 2) the PV array is subjected to partial shading condition.

This paper is structured as follows: Section II presents the main features related to the PV system including the adopted PV cell mathematical model. The MPPT techniques discussed in this paper are presented in Section III, while the results obtained from computational 
simulations are shown in Section IV. In addition, the comparative analysis involving the MPPT algorithms are also presented. Finally, Section V presents the conclusions.

\section{PV System Description}

Fig. 1 presents the electrical power circuit employed to test the performances of the MPPT algorithms. It is composed of a PV array, as well as a Boost DC-DC converter. The PV array is comprised of four series connected panels, which is able to generate maximum power around $980 \mathrm{~W}$ in STC.

In this paper the single-diode PV cell modeling was adopted, as shown in Fig. 2. It can be noted that the PV cell is modelled by a current source $\left(I_{p h}\right)$ with an anti-parallel diode $\left(D_{p v}\right)$ associated with series $\left(R_{s}\right)$ and parallel $\left(R_{p}\right)$ resistances. The complete mathematical modeling and the circuit description have been presented in detail in [11] and [12].

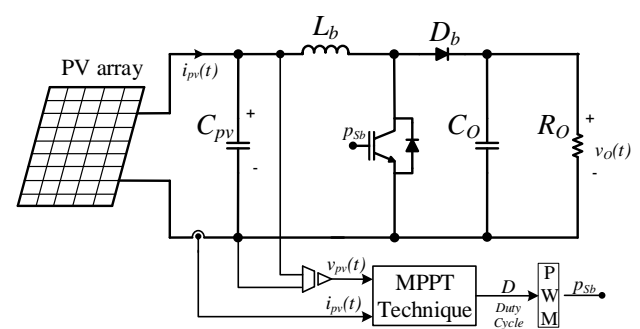

Fig. 1. PV system used to perform the MPPT.

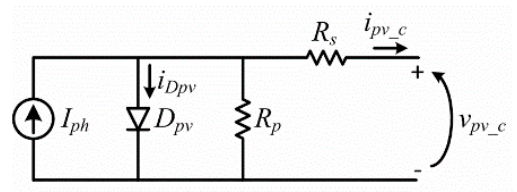

Fig. 2. PV cell equivalent circuit.

\section{MPPT Techniques}

In this section, the MPPT techniques used in this paper are presented.

\section{A. Beta Method}

The MPPT algorithm based on Beta method has been presented in [4], whose the intermediate variable $\beta$ is given by:

$$
\beta=\ln \left(\frac{i_{p v}}{v_{p v}}\right)-c \cdot v_{p v}
$$

where $v_{p v}$ and $i_{p v}$ are the respective output voltage and output current of the PV module; and $c=\left(q /\left(\eta k T N_{s}\right)\right)$ is a constant that depends on the electron charge $(q)$, the ideality factor of the cell junction $(\eta)$, the Boltzmann constant $(k)$, the temperature $(T)$ in $\mathrm{K}$ (Kelvin) and the number of photovoltaic cells inserted into the PV panel $\left(N_{s}\right)$. Fig. 3 shows the flowchart of the conventional Betabased MPPT method and its block diagram.

The $\beta^{*}$ variable of the algorithm is defined once based on PV characteristics at STC, using the MPP voltage and current, as given by (1).

$$
\beta^{*}=\ln \left(\frac{I_{m p p}}{V_{m p p}}\right)-c \cdot V_{m p p}
$$
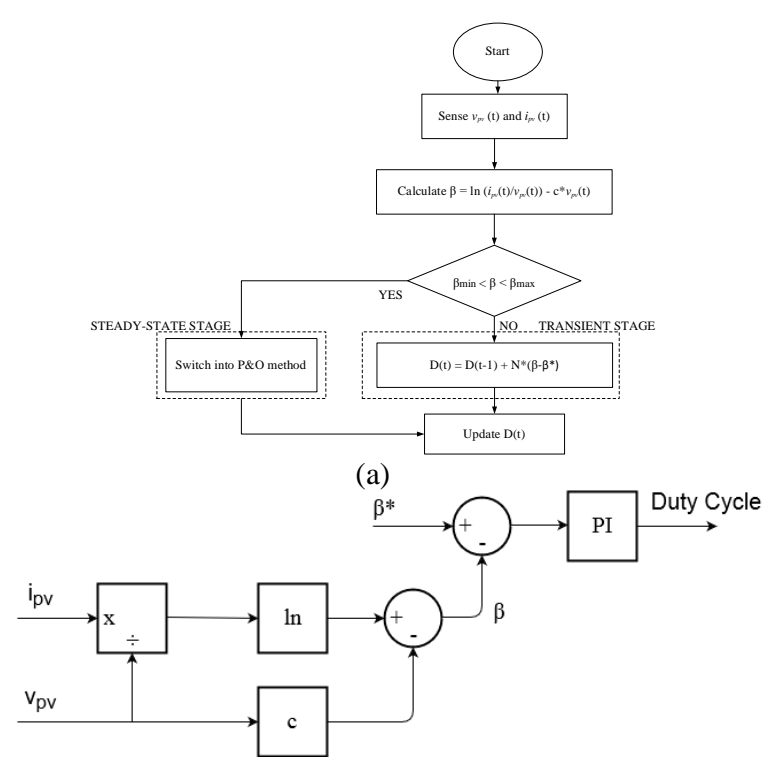

(b)

Fig. 3. Conventional Beta method: (a) flowchart, (b) block diagram.

\section{B. Perturb and Observe Method $(P \& O)$}

Depending on the adopted strategy, the P\&O-based MPPT algorithm operates increasing or decreasing the DC-DC converter duty cycle $(D)$ or adjusting the voltage reference using a fixed step size. In this paper the adopted duty cycle step size was set in $\Delta D=0.001$. The flowchart of the mentioned method is shown in Fig. 4. The main disadvantage of the P\&O-MPPT is that significant oscillations can occur around the MPP depending on the adopted step size. Furthermore, it can be trapped out in a LMPP when the PV array is subjected to partial shading. In this paper, to reduce the power oscillations at MPP, a small step size was adopted [9].

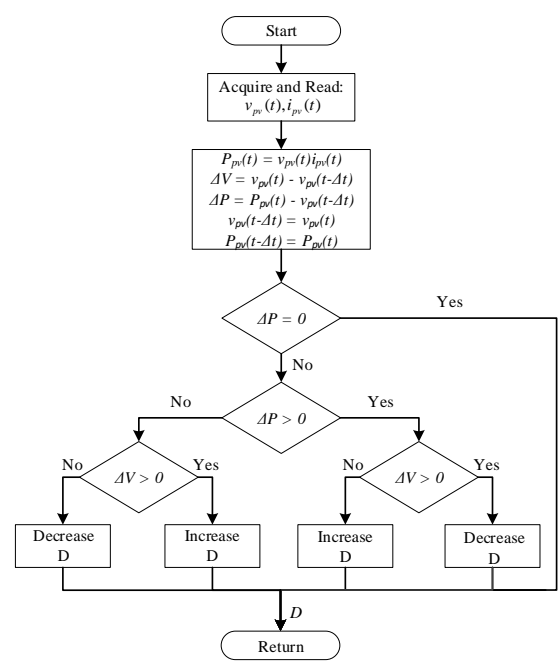

Fig. 4. P\&O-MPPT flowchart.

\section{Grey Wolf Optimization (GWO)}

The grey wolf optimization algorithm mimics the grey wolves' behavior searching for a prey, which is based on its leadership pyramid and their natural chasing process in 
nature [13]. This algorithm uses four types of wolves to emulate the hierarchy, e.g. alpha $(\alpha)$, beta $(\beta \mathrm{W})$, gamma $(\delta)$ and omega $(\omega)$. The wolf $\alpha$ is considered the best solution, thus it is considered the decision maker, as well as the leader of the pyramid. The wolves $\beta \mathrm{W}$ and $\delta$ are considered the second and third best solutions, respectively, such that they assist the wolf $\alpha$ in decisions making. Finally, $\omega$ represents the remaining wolves that follow the leaders $[9,13]$. The behavior of attack in the algorithm is represented by the following equations [9]:

$$
\begin{gathered}
\vec{e}=\left|\vec{f} \cdot \vec{x}_{p}(t)-\vec{x}_{p}(t)\right| \\
\vec{x}(t+1)=\vec{x}_{p}(t)-\vec{a} \cdot \vec{e}
\end{gathered}
$$

where $t$ is the current iteration, $a, e$ and $f$ represent the coefficient vectors, $x_{p}$ specifies the position vector of the prey and $x$ refers to the position vector of grey wolf [9]. The vectors $a$ and $f$ are computed as follows:

$$
\begin{gathered}
\vec{a}=2 \cdot \vec{b} \cdot \overrightarrow{r_{1}}-\vec{b} \\
\vec{f}=2 \cdot \overrightarrow{r_{2}}
\end{gathered}
$$

where the components of $\vec{b}$ decrease linearly from 2 to 0 ; $\overrightarrow{r_{1}}, \overrightarrow{r_{2}}$ are random vectors in $[0,1]$. For MPPT tracking presented in this paper, the duty cycle of the DC-DC converter is referred to the positions of the wolves in each state.

\section{Proposed Hybrid MPPT Technique (GWO-Beta)}

The conventional Beta method presents some limitations due to the presence of variables that depends on the PV array characteristics. Therefore, the constant $c$ and Beta reference $\left(\beta^{*}\right)$ limits the maximum power extraction from the PV array such that the method cannot operate at MPP in some cases. As shown in Fig. 3 (b), after the comparing of $\beta^{*}$ with the calculated $\beta$ parameter, the PI controller output generates the duty cycle used to control the Boost converter.

In order to overcome the limitations of the Beta method, the combination of both GWO and Beta methods is proposed with the objective to improve the convergence speed and reduce the power oscillations at the GMPP.

The proposed algorithm uses the GWO technique to achieve the global maximum power point, such that the Beta reference can be calculated according to the PV voltage and current at GMPP. After that, the MPPT algorithm is switched to the Beta method that keeps tracked on the MPP reference, guarantying the GMPP in that specific operation point. In this paper, the number of wolves chosen is equal to 3 and the number of iterations for the GWO method was set at 50 as adopted in [9]. These choices imply in the decreasing of the algorithm computational cost. Fig. 5 shows in detail the flowchart of the proposed MPPT method.

\section{Simulation Results}

Simulation results were obtained by means of MatLab/Simulink® software to verify the performance of the proposed GWO-Beta-based MPPT algorithm. The proposed MPPT algorithm is compared to well-known
P\&O-MPPT algorithm, as well as the conventional BetaMPPT and GWO-MPPT algorithms. Tables I and II show the characteristics of the PV panel and the parameters of the Boost DC-DC converter used in the computational simulations, respectively.

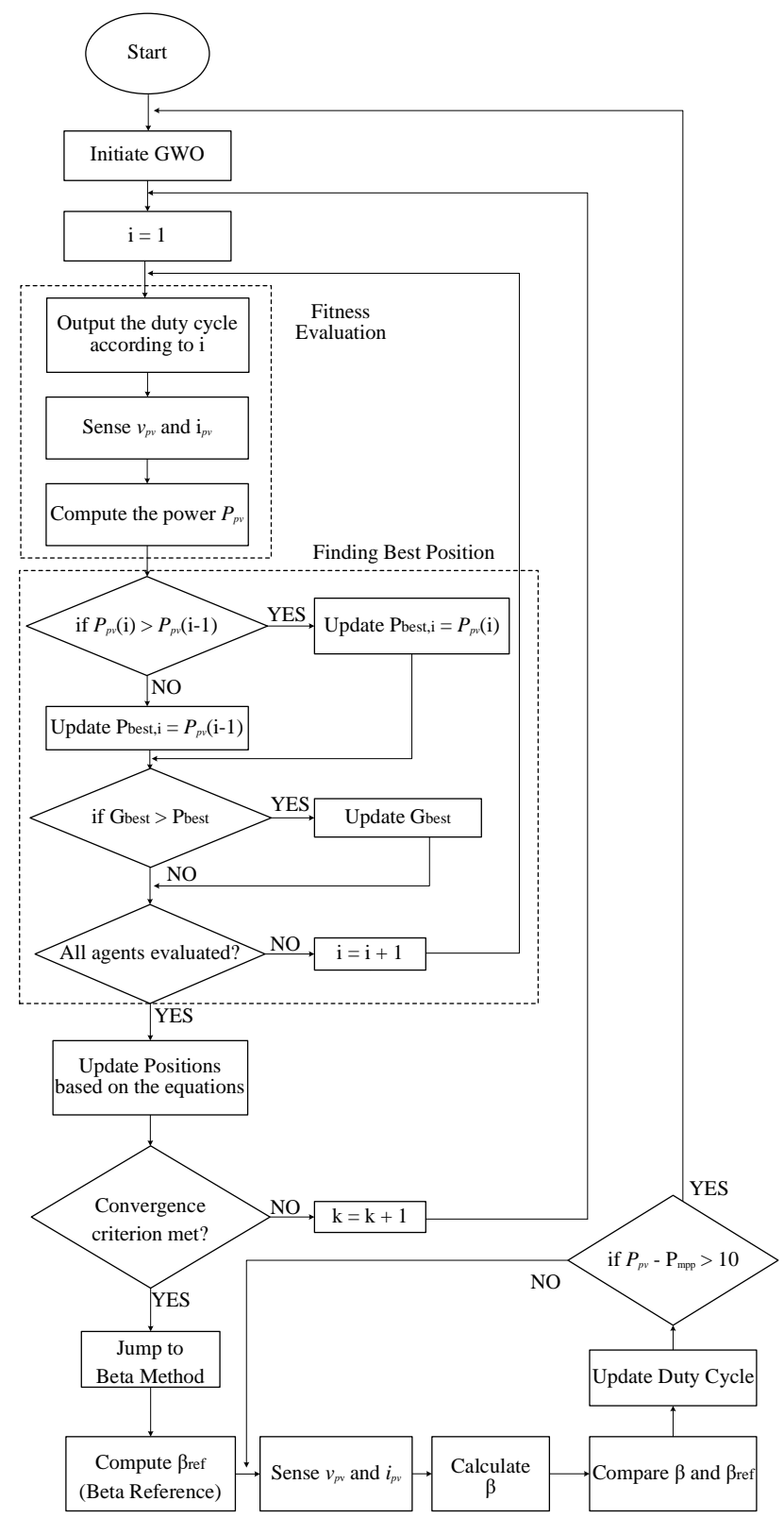

Fig. 5. Flowchart of the GWO-Beta MPPT algorithm.

Table I. - Standard Test Conditions (STC) of the SolarWorld Sunmodule Plus SW 245 PV Module

\begin{tabular}{|l|l|}
\hline Maximum PV Power & $P_{\max }=245 \mathrm{~W}$ \\
\hline MPP Voltage & $V_{m p p}=30.8 \mathrm{~V}$ \\
\hline MPP Current & $I_{m p p}=7.96 \mathrm{~A}$ \\
\hline Open-Circuit Voltage & $V_{o c}=37.5 \mathrm{~V}$ \\
\hline Short-Circuit Current & $I_{s c}=8.49 \mathrm{~A}$ \\
\hline
\end{tabular}

Table II. - Boost Converter Parameters

\begin{tabular}{|l|l|}
\hline PV Input Capacitance & $C_{p v}=100 \mu \mathrm{F}$ \\
\hline Inductance & $L_{b}=2.5 \mathrm{mH}$ \\
\hline Boost Converter Output Capacitance & $C_{O}=400 \mu \mathrm{F}$ \\
\hline Resistive Load & $R_{O}=130 \Omega$ \\
\hline Switching Frequency & $f s=20 \mathrm{kHz}$ \\
\hline
\end{tabular}


All the four MPPT algorithms were compared with each other considering the following cases: 1) Case 1: the PV array operates at STC (see Fig. 6 (a)); and 2) Case 2: the $\mathrm{PV}$ array operates under partial shading condition (see Fig. 6 (b)). In the Case 2, two PV panels operate with $300 \mathrm{~W} / \mathrm{m}^{2}$ of solar insolation. Fig. 7 presents the PV characteristic curves for the Cases 1 and 2 .

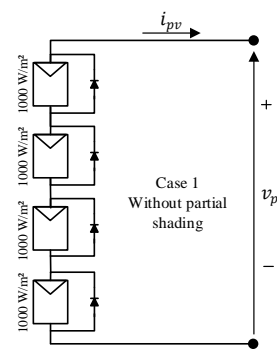

(a)

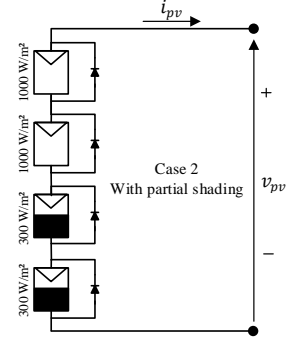

(b)
Fig. 6. PV arrangement: (a) operation considering all PV panels in STC, (b) under partial shading condition.

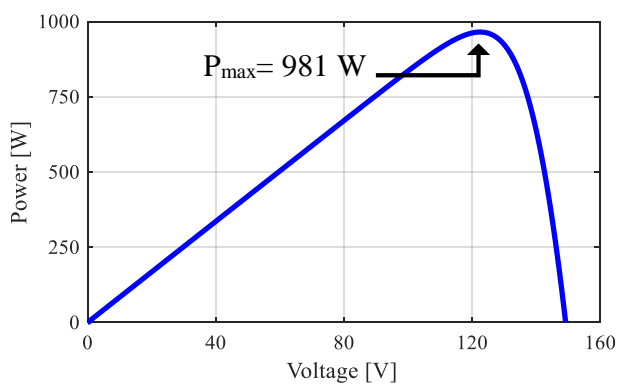

(a)

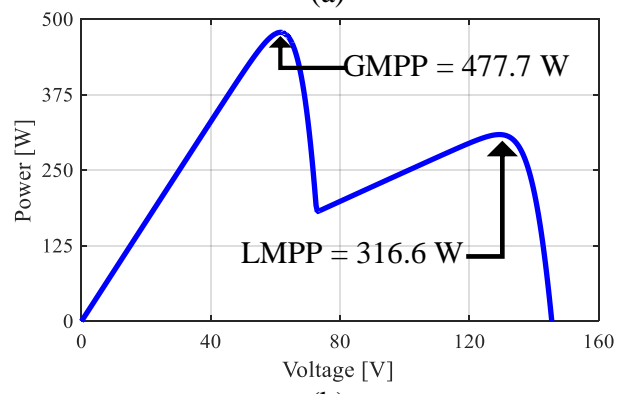

(b)

Fig. 7. Characteristic curves PpvxVpv: (a) Case 1 PV panels at STC), (b) Case 2 (PV panels under partial shading condition).

The simulation results show the PV voltage, current and power obtained for each MPPT algorithm.

\section{A. PV System Operating without Partial Shading Condition}

Fig. 8 shows the power extracted from the PV array operating without partial shading condition. As shown in Fig. 7 (a), there is only one MPP, being the maximum extracted PV power equals to $981 \mathrm{~W}$. Fig. 8 (a) shows that the P\&O-based MPPT algorithm searches the MPP, presenting low oscillations in steady-state.

The results achieved for the MPPT based on Beta Method are shown in Fig. 8 (b). It can be noted that a specific MPP is searched. However, as discussed before, due to its inherent limitations, the Beta-MPPT algorithm is not able to extract the maximum power available in PV array. On the other hand, this method also presents low oscillations in steady-state.

The results obtained for the GWO-based MPPT algorithm can be seen in Fig. 8 (c). As can be observed, MPP is achieved, however, high oscillations in steady-state are noted. Finally, Fig. 8 (d) presents the results obtained using the proposed MPPT algorithm. It can be noticed that the algorithm is able to track down the maximum power point in the PV array while presenting low power oscillations in steady state.

Table III summarizes the main results obtained from the simulation tests involving the four MPPT algorithms. The simulation results confirm that the proposed MPPT algorithm is able to converge quickly to the GMPP when the PV arrangement is operating without partial shading. Moreover, in steady state, low power oscillations occur at MPPT, as well as higher tracking efficiency is obtained when the proposed MPPT algorithm is compared to the other MPPT methods.

Table III. - Comparisons Among the MPPT Techniques for the Case 1

\begin{tabular}{|c|c|c|c|c|}
\hline PV system operation & \multicolumn{3}{|c|}{ PV array operating at STC } \\
\hline MPPT techniques & P\&O & Beta & GWO & GWO-Beta \\
\hline Time to reach MPP (s) & 0.5 & 0.22 & 0.46 & 0.46 \\
\hline $\begin{array}{c}\text { Power oscillation in } \\
\text { steady state (\%) }\end{array}$ & 1.65 & 1.05 & 2.05 & 0.19 \\
\hline $\begin{array}{c}\text { Power extracted at MPP } \\
\text { (W) }\end{array}$ & 967.6 & 967.5 & 979.6 & 980.8 \\
\hline Tracking efficiency (\%) & 98.63 & 98.62 & 99.85 & 99.98 \\
\hline
\end{tabular}

\section{B. PV System Operating under Partial Shading Condition}

Fig. 9 shows the power extracted from the PV arrangement operating under partial shading condition, which were performed taking into account the four MPPT techniques. As shown in Fig. 9 (b), the $\mathrm{P}_{\mathrm{pv}} \mathrm{x} \mathrm{V}_{\mathrm{pv}}$ characteristic curve has one GMPP and one LMPP, being the GMPP equals to 477.7W and the LMPP equals to $316.6 \mathrm{~W}$.

Fig. 9 (a) shows the results obtained for the P\&O-based MPPT algorithm. As can be noted, the LMPP was reached, as well as low power oscillations can be observed around the LMPP in steady-state. Fig. 9 (b) shows the extracted power from the PV array when Beta-based MPPT method is employed. It can be observed that the LMPP is reached, thus, it cannot be assured that this method achieves the GMPP, mainly when the temperature variation occurs in the PV array. This MPPT method also presents low power oscillations in steady-state.

Fig. 9 (c) presents simulation results for the GWO-based MPPT algorithm. It can be noted that the GMPP is achieved. However, high power oscillations in steady-state is observed. Finally, the results obtained for the proposed MPPT algorithm is shown in Fig. 9 (d). The algorithm is able to track down the MPP, while presents low power oscillations in steady state. 


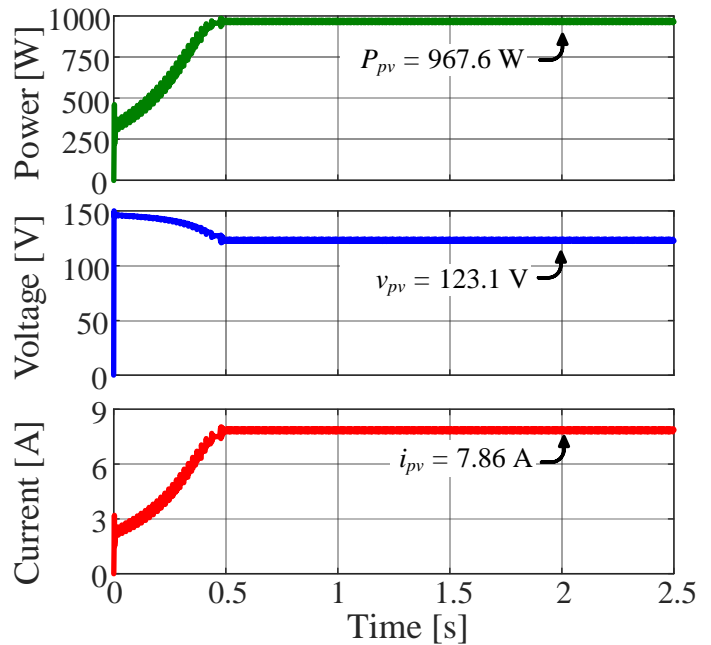

(a)

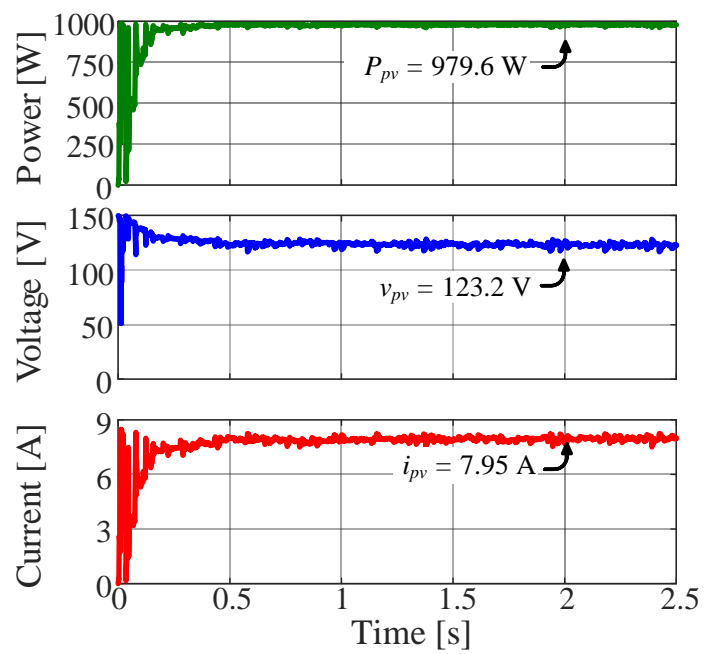

(c)

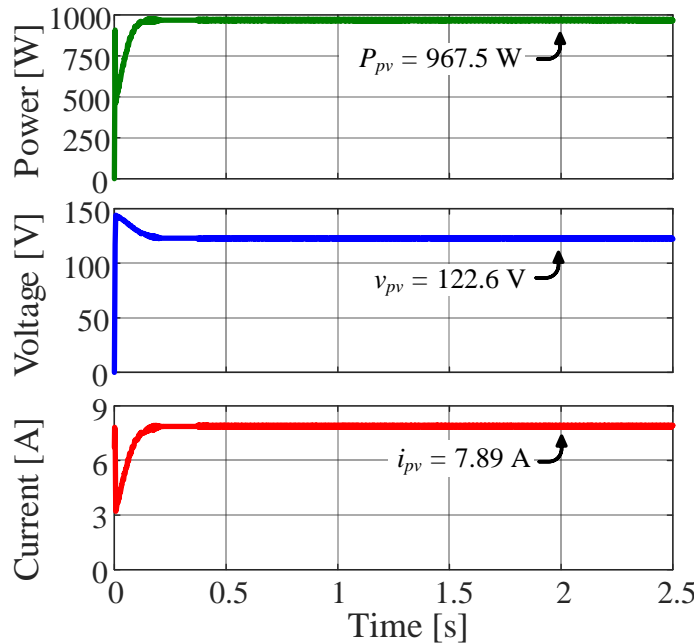

(b)
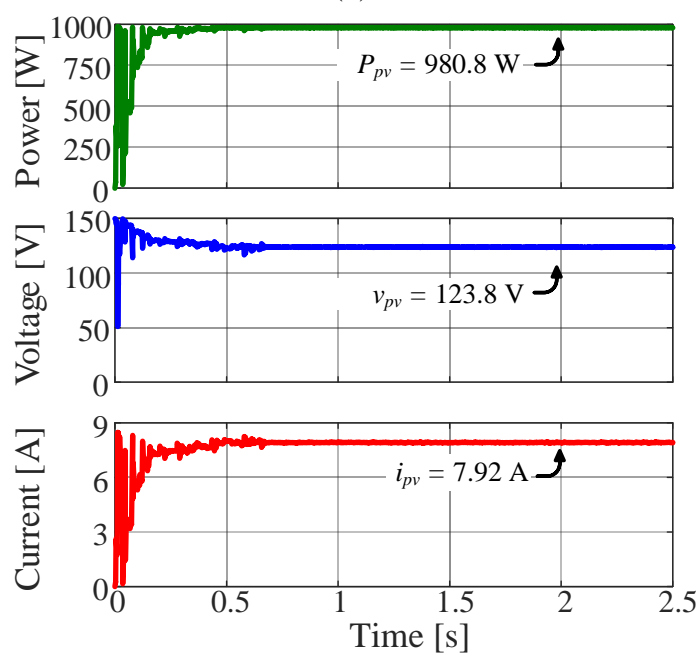

(d)

Fig. 8. Simulation results of MPPT techniques performance for case 1 (without partial shading): (a) P\&O algorithm, (b) Beta Method, (c) GWO algorithm, (d) GWO-Beta algorithm. ( $P_{p v}: 250 \mathrm{~W} / \mathrm{div} ; v_{p v}: 50 \mathrm{~V} / \mathrm{div} ; i_{p v}: 3 \mathrm{~A} / \mathrm{div}$; time $\left.0.5 \mathrm{~s} / \mathrm{div}\right)$.

Table IV summarizes the main results involving the four MPPT algorithms operating under partial shading conditions. The results confirm that the proposed MPPT algorithm is able to converge to the GMPP even when the PV array is subjected to partial shading. In addition, low power oscillations at the GMPP can be noted in steady state. It can also be observed that the proposed MPPT method presents higher tracking efficiency when compared to the other ones discussed in this paper.

Table IV. - Comparisons Among the MPPT Techniques for the Case 2

\begin{tabular}{|c|c|c|c|c|}
\hline PV system operation & \multicolumn{3}{|c|}{ PV array subjected to partial } \\
shading
\end{tabular}

This paper presented the development of a hybrid MPPT algorithm named GWO-Beta-MPPT, for effectively extract the maximum power from PV array, even operating under partial shading conditions.

The effectiveness of the proposed GWO-Beta-based MPPT algorithm was evaluated by means of simulation results, in which the proposed Hybrid MPPT technique was compared with other three MPPT techniques. Thus, it could be confirmed that the proposed MPPT algorithm presents superior performance related to higher tracking speed, faster convergence towards the GMPP, better tracking efficiency and lower power oscillations at MPP.

Finally, the proposed hybrid MPPT algorithm ensures that always the GMPP is achieved even when the PV array is subjected to partial shading conditions.

\section{Acknowledgment}

The authors gratefully acknowledge the financial support received from CNPq (Process 400837/2016-1). 


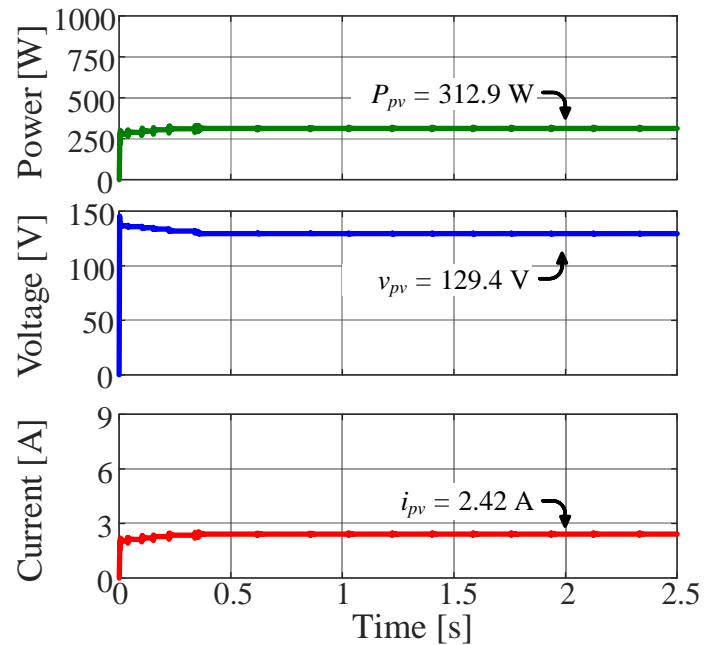

(a)

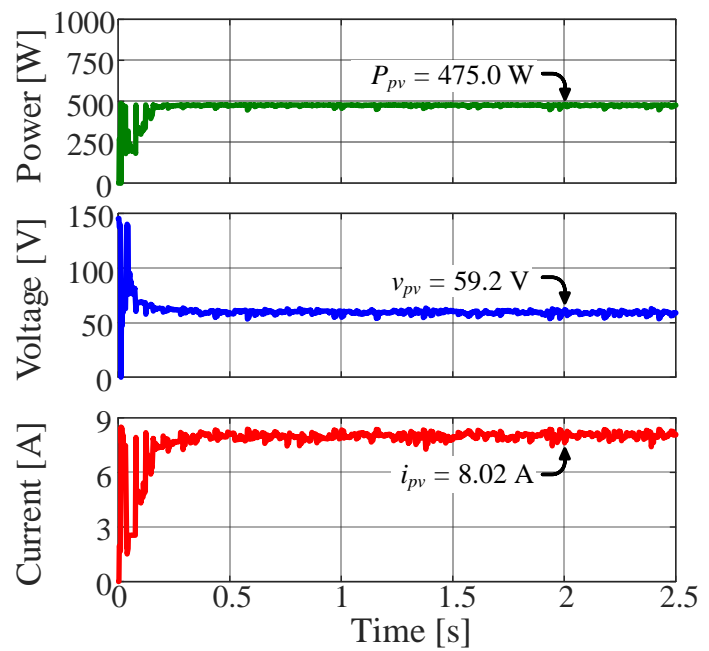

(c)
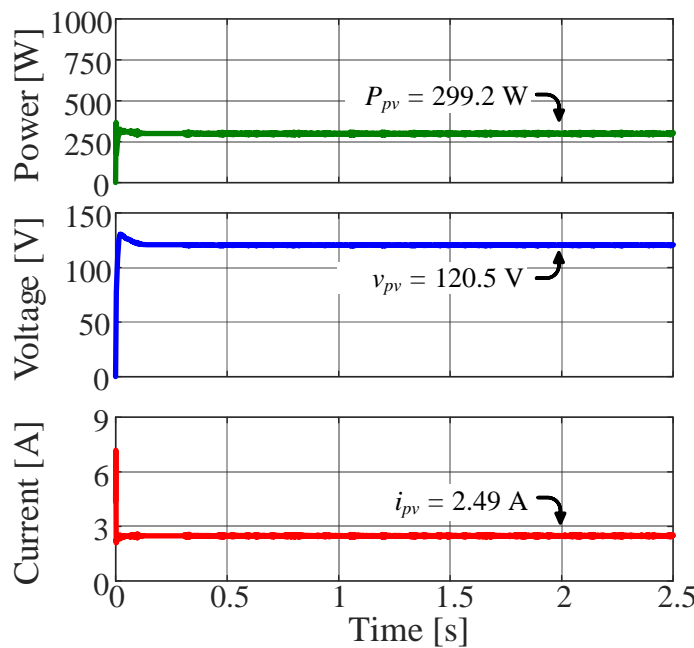

(b)
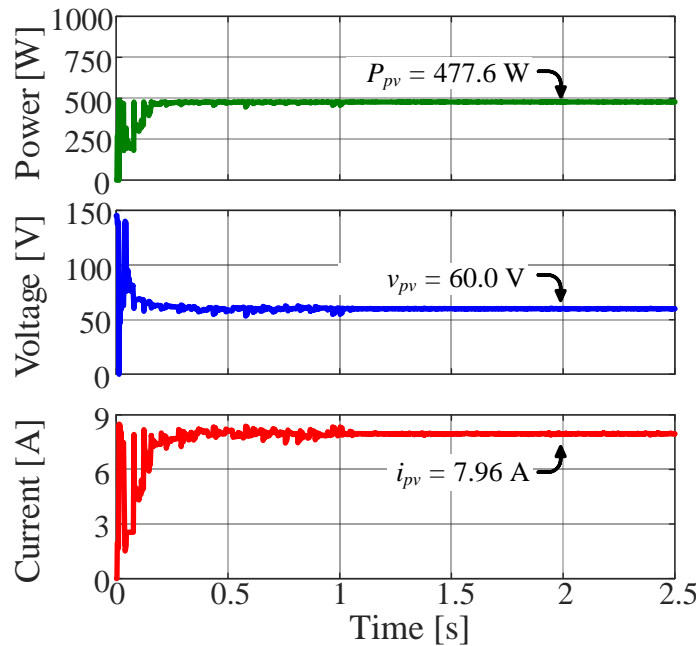

(d)

Fig. 9. Simulation results of MPPT techniques performance for case 2 (with partial shading): (a) P\&O algorithm, (b) Beta Method, (c) GWO algorithm, (d) GWO-Beta algorithm. ( $P_{p v}: 250 \mathrm{~W} / \mathrm{div} ; v_{p v}: 50 \mathrm{~V} / \mathrm{div} ; i_{p v}: 3 \mathrm{~A} / \mathrm{div}$; time $\left.0.5 \mathrm{~s} / \mathrm{div}\right)$.

\section{References}

[1] K. Catchpole, "Optical and electrical modelling for high efficiency perovskite/silicon tandem solar cells," in Proc. International Conference on Numerical Simulation of Optoelectronic Devices (NUSOD), Sydney, Australia, 2016, pp. 179-180.

[2] M. A.G. Brito, L. P. Sampaio, L. Galoto JR. and C.A. Canesin, "Evaluation of the main MPPT techniques for photovoltaic applications," IEEE Trans. Ind. Electron., vol. 60, no. 3, pp. 1156-1167, 2013.

[3] B. Subudhi and R. Pradhan, "A comparative study on maximum power point tracking techniques for photovoltaic power systems," IEEE Trans. Sustain. Energy, vol. 4, no. 1, pp. 89-98, 2013.

[4] S. Jain and V. Agarwal, "A new algorithm for rapid tracking of approximate maximum power point in photovoltaic systems," IEEE Power Electron. Lett, vol. 2, no. 1, pp. 1619, 2004.

[5] K. Ishaque, Z. Salam, A. Shamsudin, and M. Amjad, "A direct control based maximum power point tracking method for photovoltaic system under partial shading conditions using particle swarm optimization algorithm," Appl. Energy, vol. 99, pp. 414-422, 2012.

[6] K. Chen, S. Tian, and Y. Cheng, "An improved MPPT controller for photovoltaic system under partial shading condition," IEEE Trans. Sustain. Energy, vol. 5, no. 3, pp. 978-984, 2014

[7] K. Sundareswaran, V. Vigneshkumar, P. Sankar, S. P. Simon, P. S. Rao Nayak, and S. Palani, "Development of an improved $\mathrm{P} \& \mathrm{O}$ algorithm assisted through a colony of foraging ants for MPPT in PV system," IEEE Trans. Ind. Informat., vol. 12, no. 1, pp. 187-200, 2016.

[8] S. A. O. da Silva, L. P. Sampaio, F. M. de Oliveira and F. R. Durand, "Feed-forward DC-bus control loop applied to a single-phase grid-connected PV system operating with PSObased MPPT technique and active power-line conditioning," IET Renew. Power Gen., vol. 11, no. 1, pp. 183-193, 2017.

[9] S. Mohanty, B. Subudhi, and P. K Ray, "A new MPPT design using grey wolf optimization technique for photovoltaic system under partial shading conditions," IEEE Trans. Sustain. Energy, vol. 7, no. 1, pp. 181-188, 2016.

[10] S. Mohanty, B. Subudhi and P. K. Ray, "A Grey WolfAssisted perturb \& observe MPPT algorithm for a PV system," IEEE Trans. Energy Convers., vol. 32, no. 1, pp. 340-347, 2017.

[11] S. A. Rahman, R. K. Varma and T. Vanderheide, "Generalised model of a photovoltaic panel," IET Renew. Power Gen., vol. 8, no. 3, pp. 217-229, April 2014.

[12] J. A. Gow and C. D. Manning, "Development of a photovoltaic array model for use in power electronics simulation studies," IEE Proc. on Electric Power Applications, vol. 146, no. 2, p. 193-200, 1999.

[13] S. Mirjalili, S. M. Mirjalili,, Andrew Lewis, "Grey wolf optimizer," Advances in Engineering Software, vol. 69, pp. 46-61, 2014. 